\title{
Preservation of Regional Languages as New Adaptation of Phonology Learning in the "New Normal"
}

\author{
Hastari Mayrita*, Ayu Puspita Indah Sari \\ Indonesian Language Education Study Program, Faculty of Language Education and Language Teaching, Universitas Bina Darma, \\ Palembang, Indonesia
}

Received September 22, 2020; Revised December 4, 2020; Accepted December 30, 2020

\section{Cite This Paper in the following Citation Styles}

(a): [1] Hastari Mayrita, Ayu Puspita Indah Sari, "Preservation of Regional Languages as New Adaptation of Phonology Learning in the "New Normal'"," Universal Journal of Educational Research, Vol. 9, No. 3, pp. 549-555, 2021. DOI: 10.13189/ujer.2021.090314.

(b): Hastari Mayrita, Ayu Puspita Indah Sari (2021). Preservation of Regional Languages as New Adaptation of Phonology Learning in the "New Normal". Universal Journal of Educational Research, 9(3), 549-555. DOI: 10.13189/ujer.2021.090314.

Copyright $\odot 2021$ by authors, all rights reserved. Authors agree that this article remains permanently open access under the terms of the Creative Commons Attribution License 4.0 International License

\begin{abstract}
This research is a class research which uses a mixed method approach, namely a combination of qualitative and quantitative analysis. Through a qualitative approach, this classroom research seeks to reveal the phenomena that occur between teachers and learners in learning Phonetic Transcription in the Phonology course, so that a basic Phonology learning model can be obtained in the new normal era. The ethnography conducted by the researcher was modern ethnography, namely using ethnographic critics. To test the empirical research data, researchers used quantitative data. The results of the last cycle of learning in this study achieved success according to the set indicator measures. In addition, learning activities that have been carried out in this study can be carried out as an alternative to the new adaptation of Language Phonology learning in the new normal era, because this activity is supported by informatics media, namely, through e-learning, voice recording of speakers, video recordings when going into the field, and attractive and colorful image media. For the record, to overcome virtual lectures, this course in taking data to the field can be done via telephone, video call, or video conference to the resource person.
\end{abstract}

Keywords Regional Language, Phonology, New Normal

\section{Introduction}

Language is a means of communication. Without language, the communication process will not run smoothly. There are many types of languages based on the strategic location of its use; language consists of international languages, national languages, and regional languages. Therefore, it is only natural that the use of language should be adjusted according to its placement.

International languages, national languages, and regional languages are languages that need to be known and studied. But sometimes, there are still many people who only know and use their national languages and international languages, while the use of regional languages is often ignored or even abandoned. In fact, the regional language is an important asset to maintain and preserve cultural heritage.

Muslich [11] explains that language material is the sound of language; the sounds of these words are investigated by the branch of linguistics called phonology. Phonology studies the sounds of language from two perspectives. The first point of view is phonetics. Phonetics aims to study and observe language sounds as a language medium, so that these sounds form language. Meanwhile, the second point of view is Phonemic. Phonemic studies and observes the sound of words in a language which functions to distinguish meanings that are part of the language system, namely phonemes. 
Muslich explains that phonemes are the smallest sound elements of a language that serve to distinguish meaning [13]. Phonemes can be realized with several different allophones, depending on the environment (speech) [13]. Therefore, in every language, there are phoneme rules which can describe the realization of one phoneme in each environment in which it is found. Therefore, any procedure of phonological analysis, especially with regard to the case of sounds (phonemes), should record the correct corpus of data in phonetic transcription. This is because there will be lots of similar sayings in different environments. Muslich [12] also suggests that we will hear utterances from a variety of different situations.

Phonetic transcription is the recording of sounds in the form of written symbols, which are useful for knowing how to pronounce the sound of a language. According to Chaer [4], phonetic transcription is the writing of language sounds accurately and precisely by using letters or phonetic writing. Phonetic letters are made based on the modified Latin alphabet letters, or given diacritic signs. Diacritic is a sign that identifies the sounds of a language, such as in Indonesian there is a phoneme / e / in the words (lele) and (meleleh) which has difference in pronunciation and has indicated this difference in pronunciation with the presence of a diacrictic (ê) which is pronounced [ə], diakritik (é) is pronounced $[\mathrm{e}]$, and diakritik (è) is pronounced $[\varepsilon]$. So the pronunciation is /l ê $1 \hat{\mathrm{e}} /$ and / $\mathrm{m}$ é $1 \varepsilon 1 \varepsilon \mathrm{h} /$

Using language is a human right, but preserving local languages is the responsibility of every nation. As explained by Berlianty, Teng, and Balik [2] regarding Indonesian Government Regulation No. 57 of 2014 Development, Guidance and Protection of Language and Literature as well as Improving the Function of the Indonesian Language (Pengembangan, Pembinaan dan Perlindungan Bahasa dan Sastra, serta Peningkatan Fungsi Bahasa Indonesia). This regulation explains that regional languages have very large functions, namely as a formation of ethnic personalities, as an affirmation of regional identity, as well as a means of fostering and developing literature and regional culture, which can frame the diversity of Indonesian unity. So far, local languages have been used as the daily language of the community, but with a note that those who use regional languages are adults, while children up to adolescence have largely left local languages and use Indonesian in their daily conversations. Therefore, researchers try to improve understanding in the preservation of regional languages through learning in the Indonesian Language Phonology course.

Phonology is a branch of linguistics that studies the ins and outs of language sounds. One of the benefits in this field of science is the preparation of a good and correct language dictionary. The language dictionary that has been formed is very useful in preserving regional languages. Preservation of local languages is one of the things language educators and researchers need to do. Therefore, researchers also seek to improve students' understanding of the Indonesian Language Education Study Program, Bina Darma University, in the preparation of an appropriate language dictionary.

Based on the experience and involvement of researchers so far in improving student understanding in studying phonetic transcription in the Indonesian Phonology course, it is less effective. Students are less enthusiastic in learning Phonology, and they do not understand one of the benefits of learning phonology. This could be due to the lack of supervision from the teacher, so that the communication that occurs between the teacher and students in the class does not go well. This is in line with the statement which reveals that students activities in communicating with teachers is not working well, so that the supervision of every teacher in the class is also not going well, this are likely due to a lack of supervision by field supervisors [10].

Phonology is a branch of linguistics that needs to be studied and understood, especially for students of the Indonesian Language Education Study Program, because they are prospective language educators and researchers who have an obligation to preserve regional languages in Indonesia. One of the functions of phonology as a science is to assist in the preparation of language dictionaries and the preservation of regional languages. Brown [3] describes how the teaching curriculum can be structured based on functions.

The problem in this study is how learning phonetic transcription in the Indonesian Language Phonology course can function in the preservation of regional languages in the present. The benefit in this research is the new adaptation of Indonesian phonology learning in the present with the aim of making students care about the preservation of their regional language, so that they can compile a language dictionary as a means of preserving regional languages. And it is hoped that the research results applied to these students can be used as new insights in teaching students to compile language dictionaries accompanied by phonetic transcriptions, so as to help and make it easier for readers to read the sounds of pronunciation.

\section{Material Methods}

This research is a classroom research with a mixed method approach, combines a qualitative-quantitative approach. Classroom Research is a scientific study in a classroom setting that seeks to reveal the phenomena that occur between teachers and learners in learning. Chaudron's [5] study of qualitative approach used is ethnography. Mayrita, et al [9] explained the qualitative approach. Qualitative researchers have the opportunity to research various issues and aspects that are relevant and can contribute to providing a framework or basis for other questions. Creswell [6] states that ethnography seeks to explore habitual phenomena that occur within a group of 
people, so that researchers need to interact intensely with the intended object / subject. The ethnography conducted by the researcher was modern ethnography, namely using ethnographic critics. Researchers look at the habits that exist in a group of people, then look at and describe the issues that occur. In research, as described by Lincoln and Guba [8], researchers use quantitative data to see whether student learning outcomes have improved or not.

Arikunto explains about classroom research must be focused on or about things that happen in the classroom, [1]. Classroom Research is also a scientific research activity that is carried out in a rational, systematic, and reflective empirical manner towards various actions taken by teachers or lecturers (educators). Educators as well as researchers in taking action, researchers compile a plan from the beginning of the action to the assessment of the actions involved in teaching and learning activities in the classroom. This aims to improve and improve the learning conditions that have been carried out so far. In Classroom Research, empirical data are used to see whether student learning outcomes have improved or not. To test the empirical research data, researchers used quantitative data.

This research methodology applies the preparation of a regional language dictionary in learning phonetic transcription in the Indonesian Language Phonology course. This research was conducted in 2 cycles. Data collection in the first cycle was taken individually through written and oral tests and the second cycle was taken in groups through group project assignments. The results of this learning methodology will be described by the researcher as an input for a learning model in phonology courses in the current new normal era, with the aim of being able to encourage students to learn to keep creative in local language preservation through the preparation of a language dictionary.

\subsection{Location and Research Subjects}

This research was conducted at Bina Darma University. The subjects in this study were students in semester 3 (class ID3A) in the academic year 2017/2018 who attended the Indonesian Language Phonology lecture. The number of students who take this class is 7 people, with details of 1 student from abroad and 6 students from Indonesia.

\subsection{Data Source}

The source of this research data were obtained from the activities of ID3A students of the Indonesian Language Education Study Program, FKIP, Bina Darma University, $2017 / 2018$ academic year, while participating in the phonetic transcription learning process in the Phonology course.

\subsection{Type of Data}

Qualitative data in the form of findings during the implementation of was used. This data aims to find the basis of a theoretical learning model for the Phonology course as a medium for preserving regional languages in the new normal era. Quantitative data are used to test the empirical data.

\subsection{Research Procedure}

Classroom Research Procedures in this study began with the first cycle starting with four activities, namely planning, acting, observing, and reflecting. The activities in the second cycle are a continuation of the successes in the first cycle. According to [7], it explains that the entire process is the center of the learning system and is the center of other variables.

The four main activities that exist in each cycle are (a) planning, (b) action, (c) observation, (d) reflection. The learning stages carried out in this study are as follows.

a The lecturer informs about the learning indicators that will be implemented.

b The lecturer explains the importance of mastering Phonology.

c The lecturer explains the importance of local languages to be known, studied, and preserved.

d The lecturer explains the efforts to preserve local languages.

e The lecturer explains about phonetic transcription.

f The lecturer explains about speakers who can be used as research informants.

g Lecturers also provide examples of questionnaires and image media needed in conducting language research.

$\mathrm{h}$ The lecturer assigns the student the task of writing folk tales in the area using the local language, then the phonetic transcription is made and the translation into Indonesian.

i Students gain knowledge of the importance of studying material that has been discussed together in the interests of formulating phonetic transcriptions into the preparation of a regional language dictionary.

$\mathrm{j}$ The lecturer and students recall phonetic transcription and the preparation of a local language dictionary.

$\mathrm{k} \quad$ The lecturer gives the assignment to listen to his friend speaks in his local language, then writes the phonetic transcription.

1 Students take data in the field (to the area where they are observed), record the data, compile the phonetic transcription, and translate it into Indonesian.

m Students compile a local language dictionary based on the data that has been obtained.

\subsection{Data Collection Technique}

Data collection techniques in this study used: 


\subsection{Observation}

Observation is used to determine student activities during the learning process. Observations of student activities consisted of 12 observed items. The treatment that appears to students is given a score of 1 and the treatment that is not visible is given a score of 0 , so that the observation only gives a value of 1 and 0 . To make this observation the researcher uses the observation sheet. The following is a table of student activities and their scores.

\subsection{Test}

[14] states that the test as a measuring tool is said to have a level of validity if it can measure what you want to measure. The test is also a question that is given to students as feedback in understanding the material. The test is carried out at the end of each meeting in each cycle. The final test is used to see the success rate of the action taken.

\subsection{Data Analysis Technique}

This class research uses descriptive data analysis. Student ability score data were analyzed by calculating the class average score. To find the average (mean), the following formula is used:

$$
\mathbf{M x}=\frac{\sum \times}{n}
$$

Information:

$\mathrm{Mx}=$ The mean you are looking for

$\Sigma^{\mathrm{X}}=$ The sum of the scores

$\mathrm{N}=$ The multitude of scores itself

When the data have been collected, it is classified into two groups of data, namely quantitative data in the form of numbers and qualitative data expressed in symbolic words. Qualitative data in the form of words are put aside for the time being, because it will be very useful to accompany and complete the picture obtained from quantitative data analysis.

\subsection{Success Indicators}

The indicator of success is seen from the increased learning outcomes, namely with individual learning completeness if the minimum score is more than $75 \%$ of the ideal score and classical complete if more than $85 \%$ of the total student completes learning.

\section{Results and Finding}

The findings obtained from the results of the implementation of learning come from observations of researchers recorded in field notes. The results of this study are described in the form of cycles carried out in learning that takes place in the Indonesian Phonology course, in odd semester students, 2017/2018 school year, Indonesian Language Education Study Program, Faculty of Teacher Training, Education and Language, Bina Darma University. The process of implementing the action has been carried out in two cycles.

\section{Cycle Description 1}

\section{a) Planning}

After it was determined to apply the process of compiling a regional language dictionary on the phonetic transcription material in the Indonesian Phonology course, the next activity was to prepare several things that were needed at the time of implementing the action. The steps taken in cycle 1 are as follows..

1) Making learning plan and observation sheets for students during the implementation of learning in class.

2) Prepare material that will be given to students in the preparation of a regional language dictionary.

3) Prepare evaluation tools to see student learning outcomes.

\section{b) Action}

1) Researchers are directly involved in teaching and delivering subject matter. The activities carried out are described as follows.

2) Researchers explain the competencies that must be achieved as well as the benefits of the learning process and the importance of learning materials.

3) The researcher explains the learning procedure.

4) Researchers provide phonetic transcription material.

5) Researchers assign individual students to write folk tales in their regions using their regional languages into phonetic transcription, and then translate them into Indonesian.

6) Other students take turns reading the phonetic transcription written by their friend.

The number of students who completed and those who did not complete this activity can be seen in the following frequency distribution table.

Table 1. Student Frequency Distribution in Cycle I Stage

\begin{tabular}{|c|c|c|c|c|}
\hline No & Interval & Frequency & $\begin{array}{c}\text { Percentage } \\
\left(\mathbf{P}=\frac{\boldsymbol{F}}{\boldsymbol{N}} \boldsymbol{x} \mathbf{1 0 0} \%\right)\end{array}$ & Category \\
\hline 1 & $85-100$ & 0 & $0 \%$ & Excellent \\
\hline 2 & $75-84$ & 3 & $43 \%$ & Good \\
\hline 3 & $56-74$ & 3 & $43 \%$ & Enough \\
\hline 4 & $10-55$ & 1 & $14 \%$ & Less \\
\hline & Total & 7 students & $100 \%$ & \\
\hline
\end{tabular}

From the results of the table, there are no students or $0 \%$ who get the 86-100 interval with the excellent category, the acquisition of the interval with 75-84 in the good category 
is obtained by 3 students with a percentage of $43 \%$, the acquisition of the 56-74 interval with the sufficient category is obtained by 3 students with a percentage of $43 \%$, while 1 other student with a percentage of $14 \%$ obtained an interval of 10-55 with a less category.

From the table, the scores for students' ability to understand phonetic transcription in the Indonesian Phonology course in the first cycle were 3 students who had finished learning, the percentage was $43 \%$; 3 Students who do not complete, the percentage is $43 \%$; and 1 student did not complete with a percentage of $14 \%$. Based on these results, the percentage for students who did not complete the first cycle was $57 \%$.

\section{c) Observation}

Researchers always monitor the development of student attitudes, behaviors, and actions during the learning process through observation sheets. From the observation sheet data, the researcher will get an overview of the students' abilities and activeness during this lecture.

The activities observed included four assessments, namely student activities in attending lessons or attention, questioning activities and doing assignments, activities in discussion, and activities in doing evaluation. The observations made by the researchers showed that the level of students' ability to understand phonetic transcription at this stage of the first cycle was still lacking, because the actions taken during the core teaching activities were still not optimal. Based on the observations made, it was found that out of 7 students there were 7 students $(100 \%)$ of good behavior, 3 students were enthusiastic in participating in lessons, 3 other students were less enthusiastic in attending lectures (did not understand the material and assignments given), and 1 student $(22.5 \%)$ did not understand the material given at all.

\section{Description of Cycle II}

In the implementation of the actions in this cycle, the researcher explained about language screening, items that needed to be provided by Classroom Researchers in language screening, practice filling out language screening questionnaires into phonetic transcriptions, and the task of compiling a regional language dictionary - Indonesian phonetic transcription. The following is the details of the learning process carried out by Classroom Research in the second cycle:

\section{a. Planning}

Based on the results of evaluation and reflection, it is known that the implementation of the learning action in cycle I had not reached the success indicators is set by the Classroom Research. To fix the weaknesses and deficiencies identified from learning cycle 1 in the next cycle. Things that needed to be done to improve weaknesses and deficiencies in cycle II, include;
1) Researchers must be more motivated and give appreciation so that students are more active in learning.

2) Researchers must provide opportunities for students to ask on issues that are not understood.

3) Researchers must be firm and give sanctions to students who do not pay attention to the teacher's explanation.

4) Researchers must be able to manage time efficiently so that all stages of learning activities can be carried out.

The next researcher presented the results of cycle 1 and in this second cycle, the researcher put students into groups. Furthermore, researchers prepared learning materials, observation sheets for students, evaluation tools and self-reflection for cycle II actions.

\section{b. Action}

In the implementation of this II cycle action, students carried out learning to fit the action learning scenario in cycle II. Learning activities began with the teacher conveying the learning objectives to be achieved so that students have a clear picture of the knowledge that will be obtained after the learning process takes place. Lecturers also take corrective actions as planned in the second cycle. The material taught is still in the scope of phonetic transcription. However, the researcher added material regarding language screening and procedures for preparing language dictionaries. This is done so that students are even more enthusiastic in receiving and understanding material related to phonetic transcription, as well as understanding the purpose of the Phonology course through understanding phonetic transcription material. During the learning process, researchers observe the implementation of learning using observation sheets for students.

The second cycle scores were 2 students with a value range of 86-100, 4 students with a value range of 76-85, while those who did not complete were 1 student with a value range of $0-75$.

Table 2. Student Frequency Distribution in Cycle II Stage

\begin{tabular}{|c|c|c|c|c|}
\hline No & Interval & Frequency & $\begin{array}{c}\text { Percentage } \\
\left(\mathbf{P}=\frac{\boldsymbol{F}}{\boldsymbol{N}} \mathbf{x 1 0 0 \% )}\right.\end{array}$ & Category \\
\hline 1 & $86-100$ & 2 & $29 \%$ & Excellent \\
\hline 2 & $76-85$ & 4 & $57 \%$ & Good \\
\hline 3 & $56-74$ & - & $0 \%$ & Enough \\
\hline 4 & $10-55$ & 1 & $14 \%$ & Less \\
\hline & Total & 7 Students & $100 \%$ & \\
\hline
\end{tabular}

From the table, the acquisition of students' ability scores in understanding phonetic transcription material in cycle II with an average value of 75.8 and students who have completed learning are $86 \%$ or as many as 6 students and those who did not complete were $14 \%$ or as much as 1 student out of 7 existing students. 


\section{c. Observation}

In general, in the implementation of this action cycle II there was an increase in student activity compared to cycle I. This can be seen in the results of student observations, students are active and enthusiastic in learning, and the value of learning outcomes has increased from the previous cycle. Based on the observations made, it was found that out of 6 students, there were 7 students $(75 \%)$ having good behavior, and the overall learning outcomes of students on average increased from the previous cycle.

\section{d. Reflection}

Based on the results of observations and evaluation of the implementation of cycle II actions, things that still need to be considered are the use of image media as a communication tool between speakers (volunteers who are student sources in seeking information about regional language data) and interviewers (students who record the local language of the local population). This is because there are also foreign students involved in Phonology courses. The difficulty faced by foreign students studying in this class is communicating with native speakers. So, guidance for students, especially foreign students who take this class, really needs to be considered and improved.

However, with regard to the acquisition of student learning outcomes and attitudes in the second cycle, this was categorized as complete and increased from the previous cycle. Even though there is only 1 student who is yet to complete.

\section{Discussion}

During learning activities, because now learning activities in higher education are carried out virtually, the learning support activities used involve informatics media, namely, through interesting learning power points that are uploaded to e-learning, voice recordings of speakers, when going into the field (students can collect data via telephone, video call, or video conference with sources), and image media as a communication tool. The steps are as follows.

a The lecturer informs about the learning indicators that will be carried out through e-learning.

b The lecturer describes the essential material of mastering Phonology through e-learning.

c The lecturer described the importance of learning local languages, studying, and preserving them through e-learning.

d The lecturer described the efforts to preserve local languages through e-learning.

e Lecturers and students discuss phonetic transcription through video conferences.

f The lecturer describes the speakers who can be used as research informants through e-learning. g The lecturer provides examples of questionnaires and image media needed in conducting language research.

$\mathrm{h}$ The lecturer assigns the student the task of writing folk tales in the area using the local language, then the phonetic transcription is made and the translation into Indonesian.

i Students gain knowledge of the importance of studying material that has been discussed together in the interests of formulating phonetic transcriptions into the preparation of a regional language dictionary.

j Students work together in taking data in the field (to the area which is the place of observation), recording and recording the data, compiling the phonetic transcription, and translating it into Indonesian.

Note: for data collection in the field, because it is still in the middle of a pandemic, and students work in groups and share tasks in doing their assigned tasks, both in compiling dictionaries and conducting interviews (interviews can be conducted with family friends who are native speakers of regional languages) which have been agreed previously via telephone, video call, or video conference.

\section{a) Students work together to compile a local language dictionary based on the data that has been obtained.}

Research on Regional Language Preservation in Phonetic Transcription Learning has been conducted by the author ends after the implementation of the second cycle of learning because at the end of the cycle success is achieved according to the indicators. The increase in student learning activities in cycle II reached a value of 75.8 which was higher than the achievement of 65.5 in cycle I. Likewise, student learning outcomes based on learning completeness, who obtained a value $>75$ experienced a significant increase from cycle I to cycle. cycle II. The evaluation value of the test results in the second cycle classically reached $86 \%$, this percentage increased from the previous, namely in the first cycle it reached $57 \%$.

Based on the results of the assessment in cycle one, 4 students got poor grades. In the second cycle, only 1 student got poor grades. The increase in learning activities, individual assessment, and assessment of student groups occurs because learning uses phonetic transcription learning to compile a regional language dictionary, whose data sources, students get directly from native speakers by going directly to the field to dig up information about the language. 
Table 3. Recapitulation of Research Data Results

\begin{tabular}{|c|c|c|c|c|c|}
\hline No & Achievement & $\begin{array}{c}\text { Average } \\
\text { value }\end{array}$ & $\begin{array}{c}\text { Lowest } \\
\text { Value }\end{array}$ & $\begin{array}{c}\text { The } \\
\text { highest } \\
\text { score }\end{array}$ & $\begin{array}{c}\text { Finish } \\
\text { Learning }\end{array}$ \\
\hline 1 & Cycle I & 65,5 & 30 & 80 & $43 \%$ \\
\hline 2 & Cycle II & 75,8 & 30 & 88 & 86 \\
\hline
\end{tabular}

From the table, the average score of students in the first cycle was 65.5 with $43 \%$ completeness in learning, while in the second cycle the average score of students was 75.8 with $86 \%$ learning completeness..

\section{Conclusions}

The author conducted class research in this study using the mixed method approach. In addition to improving students' understanding in learning phonetic transcription and the process of taking corpus data in the field, the results of research can be used as a medium for the preservation of regional languages. The research process, starting from the preparation of teaching researchers, researchers explaining and explaining phonetic transcription and language dictionaries, researchers assign and assess student assignments individually, then students practice in the field to record regional languages to be recorded, then students compile the language into in the local language dictionary in groups. After that, the lecturer checks and assesses the students' work in terms of compiling the regional language dictionary that they have drafted.

The lecturer determines the students' learning completeness from the tasks that have been done by the students, the solidarity, and enthusiasm of the students in participating in this Phonology course. Based on the results of interviews with students, they were happy to attend this lecture. They are enthusiastic about doing the assignment given by the lecturer to preserve local languages through the preparation of a language dictionary. In addition, through this research a local language dictionary has been compiled. The language dictionary compiled by the students is the regional language of Komering, South Sumatra province, Indonesia, along with its meaning and phonetic transcription.

The process of supporting learning activities also involves informatics media, namely, through e-learning, voice recordings of speakers, video recordings when going into the field, and interesting and colorful image media. For the record, to overcome virtual lectures, this course in taking data to the field can be done via telephone, video call, or video conference to the resource person. This is so that language and literature learning in academic culture can also compete and survive in the current digital era, which globally in all fields must be ready to carry out their respective creativity in this new era.

\section{REFERENCE}

[1] Arikunto, Suharsimi, et al. (2012). Classroom action research. Jakarta: PT Bumi Aksara.

[2] Berlianty, Teng, and Agustima Balik. (2018). trengthening the Existence of Tana Language in Efforts to Protect Regional Language Laws as National Cultural Heritage. Kertha Patrika, Vol.4, No.2, 99-11. http://ojs.unud.ac.id/index.php/kerthapatrika

[3] Brown, H. (2007). Principles of Language Learning and Teaching. Fifth Edition. United States of America: Pearson Longman.

[4] Chaer, Abdul. (2009). Indonesian Phonology. Jakarta: Rineka Cipta.

[5] Chaudron, C. (1990). Second Language Classroom: Research on Teaching and Learning. Cambridge: Cambridge University Press.

[6] Creswell,J.W. (1998). Qualitative Inquiry and Research Design: Choosing Among Five Tradition. London: SAGE Publications.

[7] Dunkin, M, J and Biddle B. J. 1974. The Study of Teaching. New York: Holt, Rinchart and Winston,inc.

[8] Lincoln, Y. dan Guba, E.G. (1985). Naturalistic Inquiry. Beverly Hills: Sage Publication.

[9] Mayrita, Hastari, et al. (2019). Existence of Good and True Use Of Indonesian Language: Exploring Bilingualism and Diglossia. International Journal of Scientific \& Technology Research |IJSTR|, 8(2), 937-942. http://www.ijstr.org/paper-references.php?ref=IJSTR-1219 $-25799$

[10] Mukminin, A., Haryanto, E., Sutarno., Sari,S, R., Marzulina, L., Hadiyanto., \& Habibi, A. (2018) Bilingual education policy and Indonesian students "learning strategies. İlköğretim Online, 17(3), 1204- 1223.

[11] Muslich. (2008). Indonesian Phonology. Jakarta: Bumi Aksara.

[12] Muslich, Masnur. (2010). Indonesian Language Grammar. Jakarta: Bumi Aksara.

[13] Muslich, Masnur. (2015). Indonesian Phonology: A Descriptive Review of the Indonesian Sound System. Jakarta: Bumi Aksara.

[14] Sanjaya, Wina. (2011). Classroom action research. Jakarta: Prenada Media Group. 